\title{
Digital Editing and the Greek New Testament ${ }^{1}$
}

\author{
Hugh A.G. Houghton and Catherine J. Smith
}

The textual tradition of the Bible has inspired many of the most significant developments, principles and methodologies in editorial practice, from the parallel texts and critical symbols of Origen's Hexapla in the early third century to Lachmann's nineteeth-century stemmatics. It is therefore unsurprising that, in this digital age, the New Testament continues to be at the forefront of new and exciting initiatives. The present chapter describes the workflow and tools developed for the Editio Critica Maior of the Greek New Testament, in particular those associated with the Workspace for Collaborative Editing, and how these have shaped the task of editing both the text and documents of the New Testament and offer new models of publication thanks to the capacity of electronic media and the Internet.

The Novum Testamentum Graecum Editio Critica Maior (ЕСM) has been described as "the apotheosis of the critical edition" (Parker 2008, 200). Although it follows in the tradition of the great nineteenth-century editions of the New Testament, such as Lachmann and Buttmann (1842-1850), Tregelles (18571879), Tischendorf (1869-1884), and Westcott and Hort (1881), its comprehensive approach based on every surviving manuscript is predicated on the use of computers to acquire, analyse and publish the data associated with the edition. ${ }^{2}$ The final goal is twofold: a reconstruction of the form of text underlying all the existing evidence (the Ausgangstext, or "Initial Text") along with a presentation of variant readings from the most significant witnesses, reflecting the textual history of the first millennium. As each section of the New Testament is completed, the newly-constituted editorial text is to be adopted by the Nestle-Aland hand edition which will thus become the editio minor to the

1 This chapter draws on research from the Workspace for Collaborative Editing project, supported by the Arts and Humanities Research Counciland the Deutsche Forschungsgemeinschaft, and the COMPAUL project funded from the European Union Seventh Framework Programme (FP7/2007-2013) under grant agreement no. 283302 (COMPAUL: "The Earliest Commentaries on Paul in Greek and Latin as Sources for the Biblical Text"). An initial version was presented at the SBL Annual Meeting in Baltimore, November 2013.

2 For a recent overview of editions of the Greek New Testament, including the ECM, see Parker 2012, especially chapter 4; Wachtel 2000 provides an explanation of the initial workflow for the ЕСM and printed edition. 
more substantial presentation of the ECM. This is already the case for the Catholic Epistles, the first books to be published in the series (B. Aland et al. 2013), whose text now appears in the twenty-eighth edition of Nestle-Aland (Nestle et al. 2012) and the fifth edition of the United Bible Societies' Greek New Testament (United Bible Societies 2014).

The ECM is currently a collaborative endeavour between the Institut für neutestamentliche Textforschung in Münster (INTF), the International Greek New Testament Project (IGNTP) and the Institut für Septuaginta- und biblische Textforschung in Wuppertal (ISBTF). One of the factors making this collaboration possible is the adoption of shared software and encoding schemes. ${ }^{3}$ These have recently been brought together in the Workspace for Collaborative Editing, a joint Anglo-German project with the aim of providing a shared online environment for editorial work on the ECM. Although it is by no means unique to the Greek New Testament, the impact of digital data and electronic communications in fostering collaboration both within and between research teams is a significant advance in itself: the ease with which material and expertise can be shared in a multinational context can lead to a more consultative and mutually responsible approach between a number of partners working on overlapping projects.

The process of making an edition of the Greek New Testament is, in principle, the same as for any other work. ${ }^{4}$ As with most writings from antiquity, the autographs have not survived, although it remains possible that forms of text in circulation may reflect differing recensions produced by the author or community responsible for the earliest form of the work. The task of the editor is to identify and assemble the available evidence, making a selection from this as required; the textual data must then be compared and the variants evaluated, especially if an eclectic text is to be reconstructed based on various witnesses; the final publication must be as transparent as possible, both in presenting the primary sources and in explaining any editorial intervention. ${ }^{5}$ In printed editions, constraints of space for reasons of economy have usually led to the compression of the critical apparatus. Electronic publishing, however, allows much more freedom, with the potential for users to customise their views, such as toggling between a positive and negative apparatus, or selecting different witnesses for inclusion. The scope for extensive presentation of primary

3 The collaboration is outlined by Parker and Wachtel 2005. The main aspects of the encoding are described in Houghton 2013.

4 This is considered and described in detail in Parker 2012.

5 For further thoughts on presentation, see Elliott 1986; and Parker 2000, 36-39. 
material in a digital edition ties the editorial endeavour ever closer to the documents on which it is based, as will be explained further below.

One of the principal problems facing an editor of the New Testament is the abundance of material. Over five and a half thousand complete or fragmentary copies of the Greek New Testament survive from the period when it was transmitted by hand. A full catalogue is therefore indispensable for identifying the witnesses required for an edition. Since 1963, the index of Greek manuscripts has been the Kurzgefasste Liste der griechischen Handschriften des Neuen Testaments, maintained by the INTF (K. Aland et al. 1994). In it, each manuscript is assigned a unique identifier, known as its Gregory-Aland (or GA) number. ${ }^{6}$ Following numerous printed updates, the Liste is now available online as part of the INTF's "New Testament Virtual Manuscript Room" (NT.VMR; <http://ntvmr.uni-muenster.de/>). This electronic version can be searched by number, country and holding institution, as well as filtered by date and physical features such as the number of columns and lines on each page. The latter information is particularly important in examining potential new additions and identifying manuscripts which have changed ownership since the last available information. Further facilities currently in progress on the site include searches for biblical verses and specific codicological features, based on the crowd-sourced indexing of individual manuscripts: although it will be many years before these give exhaustive results, they are nonetheless indicative of the potential of the digital Liste to provide resources for further research.

The selection of manuscripts for the ECM is based on the Text und Textwert analysis undertaken in the second half of the twentieth century by the INTF. ${ }^{7}$ This represents one of the early uses of databases to analyse Greek New Testament manuscripts. A series of points of variation (Teststellen) were chosen in each of the New Testament writings (apart from Revelation), and the reading of every extant document recorded at that point. Texts which agreed with the majority of manuscripts are given the identifier "1," while those corresponding to the earliest text reconstructed in the Nestle-Aland edition (where this differed from the majority) are labelled "2" and further variant readings (Sonderlesarten) numbered in sequence. Given the trend towards uniformity in the textual tradition of the Greek New Testament, witnesses which deviate from the norm are more likely to preserve earlier forms of text, regardless of the age of the document. The most significant manuscripts can be identified according to their percentage agreement with the majority readings, using

6 A detailed description of the Liste is given in Parker 2008, 38-46.

7 For further description of the published volumes, see K. Aland and B. Aland 1989, 317-332. 
an appropriate cut-off point. For example, an overall agreement of $85 \%$ or less with the majority results in a group of around one hundred and twenty manuscripts for each writing, which usually includes all of the oldest, most famous, witnesses and provides the principal variant readings from the first thousand years of transmission. Experiments with raising or lowering the percentage agreement provide a way of identifying the amount of information which would be lost by choosing a particular cut-off point. The most thorough vindication of the approach is provided by the comparison of the ECM edition of Jude, relying on 140, manuscripts, with Wasserman's collation of all 560 Greek manuscripts of the epistle (Wasserman 2006): although the latter reports additional variant readings and further attestation for known alternatives, as expected, none of the significant forms are missing from the former. Interactive tools using the Text und Textwert data for the Gospels are available online. $^{8}$

The manuscripts identified for inclusion in the edition then need to be examined in full for the relevant New Testament book. Before the advent of digital reproductions, there were three ways to access the complete text of a manuscript: (1) consultation of the document in person at the holding institution; (2) microfilm or photographic images; (3) published editions or collations of individual witnesses, sometimes in the form of a facsimile. The recent move towards full digitisation of manuscripts by holding institutions (e.g. the British Library, ${ }^{9}$ the Bibliothèque Nationale de France, ${ }^{10}$ the Biblioteca Apostolica Vaticana, ${ }^{11}$ and a consortium of Swiss libraries ${ }^{12}$ ) means that consultation of a surrogate for the original is now significantly easier. Even digitised microfilm, while often of inferior quality, is still a major step forward in making images available. Furthermore, this innovation serves to broaden the user community, which formerly was normally restricted to scholars with special permission as well as funds available for travel (or acquiring reproductions); now, anyone with an internet browser can view manuscripts. One result has been an explosive increase in the discussion of these artefacts, by those with or without the "manuscript literacy" necessary for informed comment. ${ }^{13}$ The impact on criti-

8 The "Manuscript Clusters" tool at <http://intf.uni-muenster.de/TT_PP/>, last accessed February 11, 2016, earlier Text und Texwert data is not currently in a format suitable for online publication.

9 <http://www.bl.uk/manuscripts/>, last accessed February 11, 2016.

$10<$ http://gallica.bnf.fr/>, last accessed February 11, 2016.

$11<$ http://www.mss.vatlib.it/guii/scan/link.jsp>, last accessed February 11, 2016.

12 <http://www.e-codices.unifr.ch/>, last accessed February 11, 2016.

13 The need for such "manuscript literacy" was powerfully articulated by Ulrich Schmid in his contribution to the SBL 2013 panel at which the initial version of the present chapter was also delivered. 
cal editions is that they are scrutinised more than ever for the accuracy of their reporting of primary sources.

In addition to institution-based online collections (and aggregators such as $<$ http://papyri.info/>), New Testament scholars are fortunate to benefit from two discipline-based collections, the digitisation project of the Center for the Study of New Testament Manuscripts (<http://www.csntm.org $>$ ) and the NT.VMR. At present, the latter includes complete sets of images for 1634 Greek New Testament manuscripts. Some are incorporated via links to holding institutions, but the majority come from the INTF microfilm holdings which were used for the Text und Textwert analysis and subsequently digitised. A facility for indexing the biblical content of each page has been in place for a number of years in order to enable a search by biblical content: according to the graph on the homepage, 120,296 of the 578,613 images in the system have so far been indexed. ${ }^{14}$ The NT.VMR portal also includes a discussion forum for use by the 676 registered users, where links can be supplied directly to features of interest. The provision of this website by the INTF, making available resources which could already be consulted in person by visitors to Münster, has been instrumental in extending the research community in the discipline. Like many of the other features on the INTF website, it encourages collaboration by presenting the raw materials gathered for the creation of the ECM, making the process of editing more transparent and adding value to the end result.

Textual data is gathered from the selected manuscripts in the form of complete electronic transcriptions. The original motivation for this was the use of the COLLATE software developed by Peter Robinson (Robinson 1994). ${ }^{15}$ Before the advent of computers, the readings of an individual witness would be recorded as a collation, a list of differences from a standard text. However, works not with a subset of readings but a complete transcription of each manuscript. These separate files are then automatically compared to produce a critical apparatus: the comparison relies on the algorithm developed by Robinson, while the parameters which control the presentation are set by the user. At the lowest level, altering an electronic file of a reference text to represent the text of each manuscript involves the same amount of work as a paper collation but leads to considerably more flexible results. As each witness exists independently of the collation base, users are no longer bound by the choice of the reference text. The critical apparatus can be linked back to the individual transcriptions, permitting investigation of each reading in its context. The

\footnotetext{
14 <http://ntvmr.uni-muenster.de/en_GB/home>, last accessed May 13, 2014.

15 The history of this program was described online by Robinson in 2007 at $<$ http://www. sd-editions.com/blog/?p=15>, last accessed February 11, 2016; see also Robinson 20ogb.
} 
electronic files may be extended by the addition of further information, not all of it relevant to the edition. For example, the indication of abbreviations, punctuation or capital letters all serve to make each file a closer match with the original document even though they are not reported in the ECM. One of the benefits of digital media is that files can be enhanced and, where necessary, corrected without the need to start from scratch on each occasion. In addition, the automatic generation of an apparatus using COLLATE means that the emphasis remains on the transcription files: corrections are made by adjusting the files and re-collating, not by altering the output. In this way, the witnesses are authoritative, and the collation is simply an abstraction, processed data rather than primary evidence. ${ }^{16}$

This is perhaps the most significant change to the process of editing the Greek New Testament. Previously, primary data was gathered for the purpose of creating an apparatus, but then became largely redundant: a new editor had to start their data collection afresh. The shift to the digital medium leads to a new paradigm, and a double task for the editors of the first major electronic edition. First of all, they must edit the individual documents, creating an electronic archetype of each witness for the required biblical book. Only then can they proceed to use this information to edit the text itself. This explains the huge effort of transcription, which underpins the ECM, and the release of this information on websites such as the INTF's NTTranscripts and the IGNTP transcripts. ${ }^{17}$ In many cases, these provide the editio princeps of witnesses which have never previously been published in full. For others, existing editions and scholarship must be consulted in order to produce a state-of-the-art text. As part of the edition, every manuscript is being converted into electronic form: not simply digitized, in the sense of the creation of digital images, but digitalized, transcribed into a new and different medium. Modern transcribers have been seen as the copyists of today, working in the digital scriptorium to create a new version of each exemplar (thus Parker 2003, 400-401); alternatively, perhaps they should be likened to typesetters, negotiating the change in format from manuscript to edition.

Even before the work is edited, these transcription files can be re-used and analysed to create new knowledge. For example, the activity of correctors in each manuscript can be examined exhaustively based on the encoding of this

16 For more on the use of collations, and the way in which lists of readings led to an atomistic scholarly approach, see Parker 2003, 396-397. accessed February 11, 2016. It is likely that, like the images acquired by the partners in the ECM, the transcriptions will also be incorporated into the NT.VMR. 
information in a transcription. Patterns of textual division, such as section numbers or the use of capital letters and red ink, may be investigated. Files from individual books can be combined to create complete electronic editions of manuscripts, displayed alongside images on the holding institution's website. The most famous example of this is the Digital Codex Sinaiticus, combining INTF files for the New Testament with new transcriptions of the other books. ${ }^{18}$ Different editions can be created from the same transcriptions, such as the United Bible Societies Byzantine Text of John and the IGNTP edition of the Greek Majuscule Manuscripts of John (both published in print and electronic form in 2007) ${ }^{19}$ If one of the tasks of the editor is to facilitate access to the primary sources for each work, the production of electronic transcriptions which can always be updated, but remain stable in form - may be more significant than the edition itself, which must be reassembled to take account of new discoveries or research. Once the transcription files created by the ECM are made available, editors of the New Testament need never again start from scratch but will always be building on the foundations created specifically for the digital medium.

As a transcriber, however, one soon becomes aware of the limitations of electronic files in representing manuscripts. Interpreting unclear ink marks, recording unusual letter-forms or ligatures, and reporting the disposition of text on the page all pose problems when working with standard editing packages. Although it is a tempting goal to seek to create a transcription which matches the original as closely as possible, exact identity can never be achieved; what is more, the proliferation of non-standard characters corresponding to the unique features of a manuscript leads to confusion in the latter stages of collation and editing the apparatus. For this reason, the ECM has established a set of conventions in order to ensure that the focus of transcription remains on the information required for an edition of the scriptural text, including recording the reading of the first hand, any alterations made by correctors, and gaps or portions which are unclear or illegible due to damage to the document. Original spelling is always reproduced, even though much of this will be regularised out later. Following the procedures developed for COLLATE, ECM transcribers normally record details of layout in the form of page breaks,

18 <http://www.codexsinaiticus.org>, last accessed February 11, 2016 See also the online Codex Bezae, combining IGNTP and INTF transcriptions (<http://cudl.lib.cam.ac.uk/view/ MS-NN-00002-00041/>, last accessed February 11, 2016). the previous note have been reformatted and released by Logos Bible software for use on their platform. 
column breaks and line breaks, in order to allow the generation of a "textual facsimile" for each manuscript from the transcription file which forms one of the components of an electronic edition. Paratextual features such as punctuation, capital letters, the use of coloured ink, running titles at the head of each page, lectionary indications, chapter numbers and titles are included at the discretion of each project. Approaches may also differ to the recording of abbreviations: these are too common in minuscule manuscripts to merit their systematic reporting, but may be more significant in the earlier majuscule and papyrus witnesses. Part of the challenge for those leading each project has been to anticipate the future use to which the transcriptions might be put (for example, the examination of punctuation, spelling variations or other scribal practice) and to determine what information may be recorded efficiently in the first generation of digital transcription files. ${ }^{20}$

The Workspace for Collaborative Editing incorporates a number of new developments in the production of transcriptions, reflecting shifts in technology and working patterns. It also introduces new challenges. The obsolescence of COLLATE following the introduction of a new Macintosh operating system means that transcriptions can now be made directly in Unicode and be stored in the industry-standard XML format, rather than using the ASCII plain text format required for COLLATE. This results in a more streamlined workflow so transcriptions can be published as soon as they are completed rather than having to be converted to a publishable form en masse as part of the creation of the electronic edition. This simpler process also means published transcriptions can be easily updated if improvements are made to the transcriptions during the production of the edition, ensuring that the best quality transcriptions are always made available to other researchers. The adoption of an encoding format conforming to the Text Encoding Initiative (TEI) $\mathrm{P}_{5}$ Guidelines results in files which use standard markup, not requiring any additional documentation, and which are compatible with other applications designed for the TEI. The focus of the TEI on the encoding of texts rather than documents has at times led to tension in establishing a formatting for transcriptions which try to recreate page layout, although this has been accomplished without resort to any bespoke tags. ${ }^{21}$

20 For an example of the procedures adopted by the IGNTP and INTF, see the Transcription Guidelines archived at <http://epapers.bham.ac.uk/1676/>, last accessed February 11, 2016. 
One down-side of the adoption of rich XML encoding is the verbosity of the markup, making it difficult for transcribers to work natively in this environment. In order to handle this, an online transcription editor was developed as part of the Workspace, allowing transcribers to work within a what-you-seeis-what-you-mean environment. ${ }^{22}$ This replicates the display of the published transcriptions in a web browser, with line breaks matching those in the manuscript, textual decoration, the highlighting of text tagged as corrections and so on. This not only facilitates the creation of new transcriptions, but also the editing of, and addition of information to, existing files. Furthermore, the use of a series of menus for adding tags rather than having them typed individually by transcribers removes the problem of incorrectly formatted files. As with the earlier transcriptions, one challenge has been to provide scope in the XML schema and the encoding menus for all the conceivable enhancements which may be required by future users. The common standards of the ECM project and modular architecture adopted by the Workspace project mean that the transcription editor can be incorporated into other environments. It is already available in the NT.VMR which means that volunteers may contribute transcriptions from images of manuscripts which have been indexed but which have not been selected for inclusion in the edition. As with the indexing, this offers the potential over time of building up an ever more comprehensive collection of information for the use not just of scholars but of all interested parties, a textual repository to match the growing availability of images online.

The quality of transcriptions for the ECM is assured by a "double-blind" process. Two independent transcriptions are compared using the Workspace reconciler software, and the results are reviewed by an editor who resolves any discrepancies by reference to the original document. The approved file becomes the final transcription, which may then be published in its own right as well as proceeding to the next stage of the edition. In addition to making the transcriptions available through dedicated websites, mentioned above, the IGNTP files are also archived on the University of Birmingham Institutional Research Archive (<http://ubira.bham.ac.uk/>) for longer-term preservation. All transcriptions are now routinely licensed under the Creative Commons scheme, in order to ensure their availability for further re-use.

Once the revision of each document is complete, the creation of the edition begins. Computers are ideal for the purely mechanical activity of comparing the witnesses selected for the edition and producing a list of differences transcription editor can be downloaded from <http://sourceforge.net/projects/wfceote/>, last accessed February 11, 2016. 
between them. They undertake the task in a fraction of the time required for this tedious and error-prone task by previous generations. What is more, there is a gain in transparency as collations can immediately be re-run with the same settings, or even a different selection of witnesses and criteria (preserve original spelling, expand abbreviations, includes chapter numbers or lectionary markings and so on). Nonetheless, the task of collation is more sophisticated than a simple listing of data. The results have to be organised and adjusted according to scholarly requirements. This is done in a number of stages. An initial set of parameters is needed to specify information required by the edition and to disregard superfluous material, such as layout, abbreviations, ink colour, capital letters, accents, punctuation and other paratextual features. The fact that these could be included on another occasion, if desired, gives each editor the freedom to tailor their apparatus for the purpose at hand.

As noted above, the collation of the witnesses and its subsequent editing were formerly carried out using COLLATE. The Workspace for Collaborative Editing uses the designated successor to this software, the CollateX engine developed by the Interedition consortium. ${ }^{23}$ The Workspace software preprocesses the individual transcriptions to extract the readings of the different hands at places where manuscripts have been corrected, in order to treat these as separate readings. The resulting readings from each of the selected transcriptions are then aligned using CollateX, with the Workspace software acting as mediator between the editor and the CollateX software. Interactive user interfaces have been designed specifically for the creation of the ECM including drag-and-drop tools for regularising one reading to another, and for combining or splitting variants. Unlike COLLATE, where editorial procedures and requirements had largely to be accommodated to existing software capabilities, the creation of new interfaces to meet the needs of an edition with a predetermined format followed a different development model. The creation of this system has been a process of constant exchange between developers and users, first in terms of establishing the parameters for the ECM and then with regard to the editors reviewing the editorial process itself following their experience with the tools and data and suggesting alternatives. The interaction between academic and technical staff raises a new set of challenges: the management responsibilities of academics are no longer restricted to research projects but also encompass software development projects; technical staff need to make the effort to understand the academic task at hand in order to be able to write accurate user requirements; developing software alongside an

23 <http://www.interedition.eu/>, last accessed February 11, 2016. The source code is available from <http://collatex.net/>. See also Robinson 2oogb. 
edition requires a great deal of flexibility on both sides as requirements shift through the process. This interplay between scholars and programmers is characteristic of the impact of digital humanities on academic research.

The first form of editorial input is the regularisation of the initial collation. This procedure covers the removal of insignificant orthographic variation, obvious errors or supplied text where no alternative form is preserved. Although different algorithms and fuzzy matching (allowing variation in a certain number of characters before two words are identified as different) can be deployed in order to achieve a more suitable alignment of variant readings with the base text, the differences between significant and insignificant readings are too small to be left to a computer. All manipulation of data is therefore left to a scholar. The interface allows each regularisation decision to be assigned to a category as well as further explained in a free-text field. This contributes to the transparency of the edition, providing documentation of all editorial decisions. The regularisation stage of the Workspace is iterative, with the editor making a series of regularisation and then re-collating the text. The process of regularisation often improves the results from CollateX and makes the remaining stages of the editing process more straightforward. Inaccuracies which remain are then resolved by hand in the "set variants" stage. In addition to ensuring an appropriate correspondence between base text and variants, editors are able to over-rule the automatically-determined length of variation units, combining or splitting them in order to present them in the most logical way. On certain occasions, an "overlapping variant" may be created, where an alternative form which spans several other variation units and usually involves a change in word order, can be handled separately.

When the collation has been edited and arranged the data is fed into two separate editorial processes. One is a database for the application of the Coherence-Based Genealogical Method (СвGM) for establishing the initial text, which is described below. The other is the addition of secondary evidence to the apparatus. For the purpose of the ECM, these extra witnesses are restricted to biblical quotations in Greek authors of the first six centuries and early translations made directly from the Greek, including those in Latin, Coptic, Syriac and Ethiopic. The identification of biblical quotations benefits from the electronic full-text corpora of Greek writings now available, especially the Thesaurus Linguae Graecae (TLG). Keyword searching in this database has proven to be more comprehensive than the card indexes compiled earlier from scriptural indexes at the INTF, although it is still restricted by the coverage of the corpus and the ingenuity of the searcher. ${ }^{24}$ The use of the TLG also allows

24 On some of the limitations of using electronic corpora, see Harmon 2003. 
some contextual material to be recorded in the database of quotations. Despite the potential for creating links between these electronic resources, the licensing arrangements of the TLG means that this is not currently possible. Ongoing work on automated identification of quotations is currently being undertaken by a number of projects: the work of Biblindex is particularly worthy of note. ${ }^{25}$ Initiatives such as this may yet transform the discovery and use of biblical quotations. The Workspace for Collaborative Editing includes an interface for the addition of patristic and versional evidence to the collation of the Greek manuscripts: this task is undertaken by specialists in the various traditions, who also have the option to enter comments and original language readings in a dialogue box. Again, this leads to a new transparency in editorial decisions and also allows material relating to the secondary evidence to be included in a designated ECM apparatus.

The CBGM is a new way of evaluating variants in the transmission of the New Testament, made possible by the use of computers to process large amounts of data. ${ }^{26}$ Developed by Gerd Mink at the INTF, its principal contribution is to take account of textual contamination between manuscripts. In a tradition as rich as that of the New Testament, the lines of transmission are not just vertical, with texts being passed down from a single exemplar to subsequent copies, but also horizontal and diagonal, as each document was compared with (and adjusted to match) one or more others. This means that many manuscripts combine readings from different sources. In these circumstances, constructing a traditional stemma for the whole work based on shared errors or significant readings is frustrated by a mass of inconsistent and contradictory data. Instead, editors using the CBGM draw up a stemma for each variation unit, using traditional philological principles to explain how the different readings are related. The method is iterative: on the first round, the straightforward cases are entered into the interface and more complicated relationships are left alone. By recording these decisions in a database it becomes possible to describe the extent to which the entire text of one witness is prior or posterior to the text of another. This presents a provisional relationship between each witness, on the basis of which scholars can revisit the more difficult cases having been made aware of the general direction of "textual

25 See $<$ http://biblindex.org $>$, last accessed February 11, 2016. The project is further described in Mellerin 2013a; and Mellerin 2013b.

26 For introductions to the CBGM, see Mink 2011; Wachtel 2012; Parker 2012, 84-97 and the websites <http://egora.uni-muenster.de/intf/projekte/gsm_en.shtml $>$, <http://egora.unimuenster.de/intf/service/downloads_en.shtml $>$ and related links, last accessed February 11, 2016. 
flow" between the different witnesses. The principle of coherence is that the individual units of variation are related to the overall genealogical relationship of the witnesses. The software thus enables the systematic application of philological reasoning across the whole tradition. As with the programs for automatic collation, the use of computers renders the process scientifically verifiable: it can be re-run with the same or different settings in order to explore different hypotheses or take account of new information.

The chief goal of the CBGM is to enable the reconstruction of the Initial Text, the form at each point of variation which best explains the alternative readings attested in the textual tradition. Nonetheless, it also sheds new light on several features of the transmission of the New Testament. This includes identifying the forms of text which stand closest to the Initial Text. In the Catholic Epistles, there are some twenty witnesses in this first rank, each of which has as its closest ancestor the hypothetical original. This highlights the textual development which took place in the period between the creation of the text and the earliest surviving attestations: the diffusion and development into these twenty different forms must have taken place over several generations of copying. In addition, the witnesses now available to us represent only a small proportion of the total number of copies made, with the earliest period poorly represented. It is therefore important to emphasise the provisionality of the Initial Text and the further potential gap between this editorial reconstruction and the forms the autographs may have taken. The comprehensiveness of the CBGM, based on all variation units rather than a selection of readings, appears also to have sounded the death knell for the concept of geographical "texttypes" for the New Testament (e.g. "Alexandrian," "Western", "Caesarean"). ${ }^{27}$ These groupings were developed in the eighteenth and nineteenth centuries, based on readings which appeared to be characteristic of different traditions, localised according to their attestation in the biblical quotations of Christian writers. In the consolidated textual flow diagram for the whole of the Catholic Epistles, however, witnesses previously identified as belonging to the same text-type are widely dispersed, with no genealogical relationship detected between them. Finally, in offering an account of the likelihood of identical variants emerging independently within the textual tradition, the СвGM provides an insight into scribal practice: the extent to which copyists or editors were responsible for introducing an innovative reading rather than reproducing their exemplar can be quantified by this reconstruction of the textual history. ${ }^{28}$

28 An example of this is given in Wachtel 2008. 
Following the constitution of the Initial Text using the СвGM, the base text of the apparatus, which now includes the secondary evidence, is adjusted as required. The edition is now ready for publication. One of the benefits of electronic working, and the documentation of all editorial decisions along the way, is that it then becomes relatively easy to pull out the information required for the various appendices on original spelling, readings marked as errors, lectionary-influenced readings, references for patristic quotations, discussions of versional evidence and so on. Although the raw materials relating to the construction of the ECM are made available online, it remains to be seen whether an electronic publication of the edition itself will accompany the printed version. ${ }^{29}$

The above account of the workflow to produce the ECM has shown how digital tools and approaches are integral to each stage of the process. The scope of this large-scale project is only practicable with the processing power of computers and electronic storage and retrieval. What is more, the interaction between philological practice and the development of digital methods and standards during the project serves as an illustration of the partnership which characterises the field of digital humanities. ${ }^{30}$ The move to an electronic medium has resulted in a new editorial task: editing each document in the form of a digital transcription, which will serve as an exemplar for future research as well as a primary source for the creation of new editions. This shift back to the individual artefacts, despite long being a tenet of textual scholarship, ${ }^{31}$ has been accelerated by the increasing online availability of complete digitisations of manuscripts. The creation of a corpus of electronic text, in a standard form of encoding, to match these images, further opens up the textual tradition to new forms of inquiry. The role of these transcriptions as building-blocks of an edition, to be handled by bespoke electronic tools, is exemplified by the two key pieces of software in the production of the ECM: the automatic collation tool and the СвGм. In both cases, the primary data remains unaltered, but value is added to it through editorial input in order to come to a clearer understanding and presentation of the data. This division between data and metadata results

29 Among the resources already available online are the Genealogical Queries program (<http://intf.uni-muenster.de/cbgm/index_en.html>, last accessed February 11, 2016) and the Parallel Pericopes apparatus (<http://intf.uni-muenster.de/PPApparatus/>, last accessed February 11, 2016); for further links, see <http://egora.uni-muenster.de/intf/>, last accessed February 11, 2016.

30 Amidst the wide literature on this subject, see Burnard, O'Brien O'Keeffe, and Unsworth 2006; Parker 2012; Robinson 2009a; 2013.

$3^{1} \quad$ Epitomised in F.J.A. Hort's dictum that "Knowledge of documents should precede final judgement upon readings" (Westcott and Hort 1881, 31). 
in significant gains of transparency in the creation of the edition: the documentation of all scholarly decisions and the possibility of tracing all editorial activity, verifying it through links to digital surrogates of manuscripts or the complete text of early Christian authors, holds editors up to greater scrutiny than ever. Nevertheless, this is entirely in keeping with the responsibility of editors to offer a gateway to the primary sources as part of a critical edition.

To what extent does this affect the concept of a critical edition? On one level, the first editors of the New Testament in a digital medium are privileged in their double task of preparing both the primary sources and the critical edition. At the same time, it has been suggested that the provision of more and more primary sources would change the nature of the edition. ${ }^{32}$ As long ago as 1934, Victor Leroquais referred to "Modern scholars, who require not so much a text as the materials to create their own"33 (Leroquais 1934, 250). In this respect, the ECM follows the same paradigm as electronic editions of the Canterbury Tales Project, Dante's Monarchia and Commedia and portals such as Transcribe Bentham and Ancient Lives. ${ }^{34}$ The provision of transcriptions of individual manuscripts, with the potential to view variation synoptically without privileging any one text, is comparable to the Homer Multitext Project. ${ }^{35}$ At the same time, the creation of a critically reconstructed text from these borndigital primary materials is one of the distinctive features of the ECM, particularly in terms of the scale of the textual tradition. While the proliferation of "pick and mix" editions, in which editors with various degrees of expertise make their own eclectic selection from attested variants, might be a possible offshoot of this abundance of materials, in practice this seems less likely: critical editions have long provided such repositories of alternative readings, and the resources required for the creation of a scholarly edition remain considerable. The effort involved in not only gathering the data but also organising and analysing it indicate that the constitution of a critical text will continue to remain in the hands of a relatively small band of editors. ${ }^{36}$

32 e.g. Parker 2003, 404.

33 "Les érudits modernes, qui réclament non pas tant un texte que des matériaux pour s'en faire un."

34 See <http://www.petermwrobinson.me.uk/canterburytalesproject.com/>, <http://www. sd-editions.com/index.html>, <http://blogs.ucl.ac.uk/transcribe-bentham/> and <http:// www.ancientlives.org/>, all last accessed January, 9, 2014.

35 <http://www.homermultitext.org/>, last accessed February 11, 2016.

36 In addition to the ECM and its related hand editions, recent developments in the sphere of the New Testament include the creation of the $S B L$ Greek New Testament by Michael W. Holmes in 2010 and the ongoing Tyndale House Edition of the Greek New Testament, both by scholarly editors. 
Electronic resources and communications, however, have also served to increase and diversify the community engaged in the study of these texts and documents. While the specialist linguistic and palaeographical skills required mean that the Greek New Testament is probably less likely to benefit from crowd-sourcing than other textual traditions, the establishment of the NT.VMR by the INTF as a central, authoritative portal with a range of user-contributed tasks is a significant step in the "democratization of scholarship," increasing the potential for volunteer contributions and public engagement with this material. At the same time, the online publication of tools and resources extends participation to researchers from countries with few or no institutions holding primary sources, which have not traditionally been active in the discipline. The readiness of the international range of partners in the ECM to collaborate in this endeavour, sharing procedures, software, resources and expertise, sustained both by digital tools and personal contact, should also be hailed as a welcome advance which brings this long-awaited edition closer. Eldon Epp famously - and controversially - characterised the twentieth century as an "interlude" in New Testament textual criticism, going so far as to suggest its imminent demise (Epp 1974; Epp 1979). ${ }^{37}$ At the beginning of the twenty-first century, the discipline is in good health, with the editorial task and associated research questions renewed by the advent of the digital age.

\section{References}

Aland, Barbara, Kurt Aland, Gerd Mink, Holger Strutwolf, and Klaus Wachtel, eds. 2013. Novum Testamentum Graecum. Editio Critica Maior. Vol. Iv: Catholic Letters. 2nd ed. Stuttgart: Deutsche Bibelgesellschaft.

Aland, Kurt, and Barbara Aland. 1989. The text of the New Testament: An Introduction to the Critical Editions and to the Theory and Practice of Modern Textual Criticism. Translated by Erroll F. Rhodes. 2nd ed. Grand Rapids, Mich.: W.B. Eerdmans Pub. Co. Aland, Kurt, Michael Welte, Beate Köster, and Klaus Junack. 1994. Kurzgefasste Liste der griechischen Handschriften des Neuen Testaments. 2nd ed. (first edition 1963), enlarged. Arbeiten zur neutestamentlichen Textforschung 1. Berlin/ New York: W. de Gruyter.

Burnard, Lou, Katherine O'Brien O'Keeffe, and John Unsworth, eds. 2006. Electronic Textual Editing. New York: Modern Language Association of America.

Elliott, James Keith. 1986. "The Purpose and Construction of a Critical Apparatus to a Greek New Testament." In Studien zum Text und zur Ethik des Neuen Testaments: Festschrift zum 8o. Geburtstag von Heinrich Greeven, edited by Wolfgang Schrage.

37 For an assessment of these articles and further bibliography, see Hurtado 1999. 
Beihefte zur Zeitschrift für die neutestamentliche Wissenschaft und die Kunde der älteren Kirche 47. Berlin: Walter de Gruyter.

Epp, Eldon Jay. 1974. "The Twentieth Century Interlude in New Testament Textual Criticism." Journal of Biblical Literature 93: 386-414.

—. 1979. "New Testament Textual Criticism in America: Requiem for a Discipline." Journal of Biblical Literature 98: 94-98.

Harmon, Steven R. 2003. "A Note on the Critical Use of Instrumenta for the Retrieval of Patristic Biblical Exegesis." Journal of Early Christian Studies 11: 95-107.

Houghton, Hugh A.G. 2011. "Recent Developments in New Testament Textual Criticism." Early Christianity 2: 245-68.

. 2013. "The Electronic Scriptorium: Markup for New Testament Manuscripts." In Digital Humanities in Biblical, Early Jewish and Early Christian Studies, edited by Claire Clivaz, Andrew F. Gregory, and David Hamidović, 31-6o. Scholarly Communication 2. Leiden: Brill.

Hurtado, Larry W. 1999. "Beyond the Interlude? Developments and Directions in New Testament Textual Criticism." In Studies in the early text of the Gospels and Acts: the papers of the First Birmingham Colloquium on the Textual Criticism of the New Testament, edited by David G.K. Taylor, 26-48. Birmingham: Univ. of Birmingham Press.

Lachmann, Karl, and Philipp Buttmann. 1842-1850. Novum Testamentum Graece et Latine. 2nd ed. 2 vols. Berlin: Reimer.

Leroquais, Victor. 1934. "Review of Hippolyte Delehaye et Henri Quentin, Acta Sanctorum Novembris (1931); Hippolyte Delehaye, Les Origines Du Culte Des Martyrs (1933)." Revue D’histoire de l'Église de France 20: 249-52.

Mellerin, Laurence. 2013a. "Methodological Issues in BiblIndex, An Online Index of Biblical Quotations in Early Christian Literature." In Biblical quotations in patristic texts : studia patristica, vol. 54, edited by Laurence Mellerin, Markus Vinzent, and Hugh A.G. Houghton, 11-32. Leuven: Peeters.

- 2013b. "New Ways of Searching with Biblindex, the Online Index of Biblical Quotations in Early Christian Literature." In Digital Humanities in Biblical, Early Jewish and Early Christian Studies, edited by Claire Clivaz, Andrew F. Gregory, and David Hamidović, 175-92. Scholarly Communication 2. Leiden: Brill.

Mink, Gerd. 2011. "Contamination, Coherence, and Coincidence in Textual Transmission." In The Textual History of the Greek New Testament: Changing Views in Contemporary Research, Text-Critical Studies, Number 8, edited by Klaus Wachtel and Michael W. Holmes, 4:141-216. Novum Testamentum 54. Atlanta: Brill.

Nestle, Eberhard, Erwin Nestle, Barbara Aland, Kurt Aland, Johannes Karavidopoulos, Carlo Maria Martini, Bruce M. Metzger, and the Institute for New Testament Textual Research Münster/Westphalia. 2012. Novum Testamentum Graece. 28th ed. revised. Stuttgart: Deutsche Bibelgesellschaft. 
Parker, David C. 200o. "The Text of the New Testament and Computers: The International Greek New Testament Project." Literary and Linguistic Computing 15 (1): 27-41. . 2003. "Through a Screen Darkly: Digital Texts and the New Testament." Journal for the Study of the New Testament 25 (4):395-411.

- 2008. An Introduction to the New Testament Manuscripts and Their Texts. Cambridge: Cambridge University Press.

. 2012. Textual Scholarship and the Making of the New Testament. Lyell Lectures. Oxford: Oxford University Press.

Parker, David C., and Klaus Wachtel. 2005. "The Joint IGNTP/ INTF Editio Critica Maior of the Gospel of John: Its Goals and Their Significance for New Testament Scholarship." Paper Delivered at the Annual Meeting of SNTs, August 2-6, 2005. <http://epapers. bham.ac.uk/754/>.

Robinson, Peter M.W. 1994. Collate: Interactive Collation of Large Textual Traditions, Version 2. (Computer Program distributed by the Oxford University Centre for Humanities Computing: Oxford).

- 2009a. “The Ends of Editing." Digital Humanities Quarterly 3 (3).

- 2009b. "Towards a Scholarly Editing System for the Next Decades." Lectures Notes in Computer Sciences 5402: 346-57.

- 2013. "Towards a Theory of Digital Editions." Variants 10: 105-31.

von Tischendorf, Constantin. 1869-1884. Novum Testamentum Graece ... Editio Octava Critica Maior. 3 vols. Leipzig: Giesecke \& Devrient.

Tregelles, Samuel Prideaux. 1857-1879. The Greek New Testament. 7 vols. London: S. Bagster and Sons [and] United Bible Societies, 2014. The Greek New Testament, $5^{\text {th }}$ ed. revised. Stuttgart.

Wachtel, Klaus. 2000. "Editing the Greek New Testament on the Threshold of the TwentyFirst Century." Literary and Linguistic Computing 15 (1): 43-50.

. 2008. "Towards a Redefinition of External Criteria: The Role of Coherence in Assessing the Origin of Variants." In Textual Variation: Theological and Social Tendencies? Papers from the Fifth Birmingham Colloquium on the Textual Criticism of the New Testament, edited by David C. Parker and Hugh A.G. Houghton, 109-27. Texts and Studies 3. Piscataway, NJ: Gorgias Press.

2012. "The Coherence-Based Genealogical Method: A New Way to Reconstruct the Text of the Greek New Testament." In Editing the Bible: Assessing the Task Past and Present, edited by John S. Kloppenborg and Judith H. Newman, 123-38. Resources for Biblical Study 69. Atlanta: Society of Biblical Literature.

Wasserman, Tommy. 2006. The Epistle of Jude: Its Text and Transmission. Coniectanea Biblica, New Testament Series 43. Stockholm: Almqvist \& Wiksell International. Westcott, Brooke Foss, and Fenton John Anthony Hort. 1881. The New Testament in the Original Greek. Introduction and Appendix. Cambridge: Macmillan. 